\title{
Triphenylamine corrole dyads: Synthesis, characterization and substitution effect on photophysical properties
}

\author{
KOLANU SUDHAKAR and LINGAMALLU GIRIBABU* \\ Inorganic \& Physical Chemistry Division, CSIR-Indian Institute of Chemical Technology, Tarnaka, \\ Hyderabad, Telangana, 500 007, India \\ Email: giribabu@iict.res.in
}

MS received 10 November 2016; revised 7 December 2016; accepted 8 December 2016

\begin{abstract}
We present our results on the effect of substitution on the photophysical properties of donoracceptor (D-A) systems in which triphenylamine is the donor and substituted corroles i.e., 5,15-phenyl-10triphenylaminecorrole TPACor 1, 5,15-di(3,5-ditertbutylphenyl)-10-triphenylaminecorrole TPACor 2, and 5,15-(4-nitrophenyl)-10-triphenylaminecorrole TPACor $\mathbf{3}$ is the acceptor. All three dyads have been characterized by elemental analysis, MALDI-MS, cyclic voltammetry, UV-Vis and fluorescence (steady state and timeresolved) spectroscopies. Both Soret and Q bands of TPACor 3 are red-shifted when compared to other two dyads due to the presence of electron withdrawing nitro group. Similarly, redox properties of TPACor 3 are altered, when correlated to TPACor 1 and TPACor 2 dyads. However, the fluorescence emission of triphenylamine in all three dyads was quenched significantly (>90\%) compared to its monomeric unit. The presence of either electron releasing or electron withdrawing group on corrole moiety has not much effect on the photophysical properties. The quenched emission was attributed to intramolecular excitation energy transfer and the photoinduced electron transfer reactions contested in these dyads.
\end{abstract}

Keywords. Triphenylamine; corrole; dyad; intramolecular energy transfer, time-resolved fluorescence.

\section{Introduction}

Natural photosynthesis is one of the major pathways that render the solar energy conversion into in biological systems. ${ }^{1-7}$ Nature performs such energy conversions by the light-driven molecular machinery of well stacked chlorophyll pigments and its associated antennae modules. ${ }^{8}$ The reason behind of this investigation is to enquire about new artificial molecular systems mimicking the primary phenomena of natural photosynthesis. A wide range of photosynthesis investigations have led to the understanding of various aspects of this intriguing process, in addition to potential applications. ${ }^{9}$ For this reason various supramolecular dyads, triads, tetrads, etc., have been designed to understand the initial events of natural photosynthesis. ${ }^{10-14}$ In this context, porphyrin is the primary photoactive species to demonstrate the natural photosynthetic process by easy synthetic manipulations, which resembles the chlorophyll pigment. However, the need for the performance improvement and increase in the variety of such molecular systems encouraged the use of other porphyrinoids. In this regard, corroles are excellent materials to investigate the photoinduced reactions.

\footnotetext{
*For correspondence
}

Corroles are one carbon short analogues of porphyrins, and its its applications have rapidly increased after the development one-pot synthesis in 1999. ${ }^{15-17}$ In recent years, studies on corrole have received much attention because of their potential applications. Corroles are tribasic aromatic macrocycles which exhibit lower oxidation potentials, stabilize higher oxidation states and interesting photophysics. ${ }^{18-20}$ The fundamental photophysical behaviour of corroles has been studied and these aromatic tetrapyrrolic macrocycles exhibit some interesting properties when compared to porphyrin: higher fluorescence and lower phosphorescence quantum yields, larger Stokes shifts and greater absorption of the red light. ${ }^{21}$ The potentiality of stable corroles depends on their ability to display within the arrays either efficient energy or electron transfer process following light absorption. In the design of photoactive arrays, corroles can play the role of energy acceptors more easily than that of energy donors, due to their relatively low excited state energy level; examples are triphenylamine-corrole, ${ }^{21}$ coumarin-corrole, ${ }^{22}$ ferrocene-corrole, ${ }^{23,24}$ phenathiazine-corrole, ${ }^{25}$ carbazolecorrole, ${ }^{26}$ BODIPY-corrole, ${ }^{27}$ porphyrin-corrole, ${ }^{28,29}$ etc . In addition, they have been employed as electron donors rather than electron acceptors, due to the relative ease of oxidation of their macrocycle, depending on the 


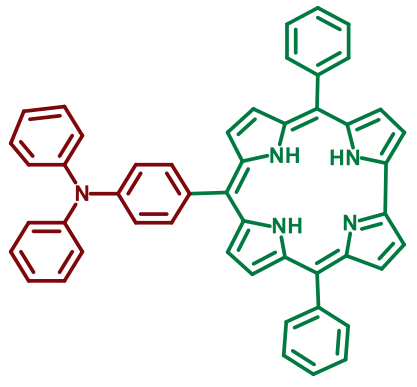

TPACor 1

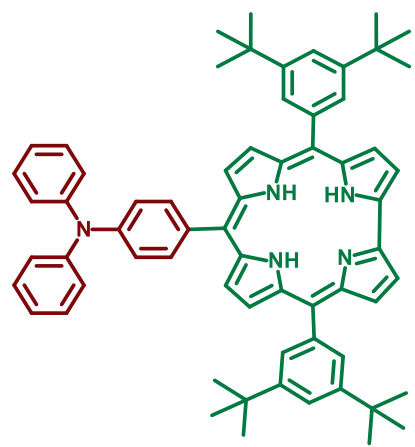

TPACor 2

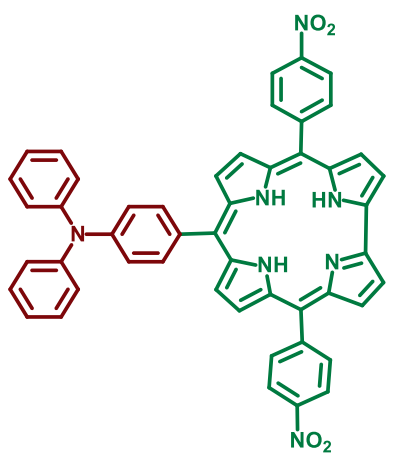

TPACor 3

Chart 1. Molecular structures of TPACor 1, TPACor 2, and TPACor 3.

substitution pattern; as in the case of corrole-fullerene, ${ }^{30}$ corrole-napthalimide, ${ }^{31}$ corrole-perlynbisimide,${ }^{32}$ corroleanthraquinone, ${ }^{33}$ etc.

Recently, we have demonstrated the photoinduced reactions in the triphenylamine corrole dyad systems, with and without ethylphenyl spacer. ${ }^{21}$ In these dyad systems the photophysical process was explained by energy transfer reaction competing with electron transfer reaction from singlet state of triphenylamine to corrole. Here, in the present manuscript, we have studied the effect of photoinduced reactions by introducing electron donating and withdrawing groups at meso-phenyl rings 5,15-pheny-10-triphenylaminecorrole TPACor 1, 5,15-di(3,5-ditertbutylphenyl)-10-triphenylaminecorrole TPACor 2, and 5,15-(4-nitrophenyl)-10-triphenylaminecorrole TPACor 3 (Chart 1). It is known in literature that the addition of one or more $-\mathrm{NO}_{2}$ groups to a corrole macrocycle significantly alters chemical and physical properties. Three types of nitro-substituted corroles have been reported: (i) meso-substituted nitrocorroles, ${ }^{34}$ (ii) $\beta$-pyrrole substituted nitrocorroles, ${ }^{35,36}$ and (iii) meso-phenyl substituted nitrocorrole. ${ }^{37}$ The photostability of corroles are enhanced by the presence of electron-withdrawing groups in its molecular structure. $^{38}$

\section{Experimental}

\subsection{Materials}

Commercially available reagents, chemicals and chloroform$\mathrm{d}_{3}$ were procured from Sigma-Aldrich. Analytical reagent grade solvents were used for synthesis and commercial grade solvents distilled prior to use in the column chromatography. Dichloromethane, chloroform and acetonitrile were dried over calcium hydride under nitrogen atmosphere. Toluene, hexane and cyclohexane were purified by stirring overnight with sodium metal under nitrogen atmosphere. ACME silica gel (100-200 mesh) was used for column chromatography.
Thin-layer chromatography performed on Merck-precoated silica gel 60-F254 plates. Either gravity or flash chromatography was performed for purification of all compounds. All the reactions were carried out under nitrogen atmosphere using dry and degassed solvents in the absence of light.

\subsection{Synthesis}

5-Phenyldipyrromethane (DPM 1), ${ }^{39}$ 5-(3,5-ditertbutylphenyl) dipyrromethane (DPM 2), ${ }^{40,41}$ 5-(4-nitrophenyl)dipyrromethane (DPM 3), ${ }^{39}$ 4-(diphenylamino)benzaldehyde (TPA-CHO), ${ }^{42}$ 5,10,15-triphenyl corrole (TPC), ${ }^{17}$ and 10-triphenylamine5,15-diphenylcorrole (TPACor $\mathbf{1})^{21}$ were synthesized as per reported procedures.

\subsubsection{0-triphenylamine-5,15-di(3,5-diterbutylphenyl)corrole}

(TPACor 2): 4-(Diphenylamino)benzaldehyde (TPA-CHO) (0.5 gm, $1.83 \mathrm{mmol})$ and 5-(3,5-diterbutylphenyl)dipyrromethane (DPM 2) (1.21 gm, $3.66 \mathrm{mmol})$ were dissolved in $\mathrm{MeOH}(100 \mathrm{~mL})$. Subsequently, the solution of $\mathrm{HCl}_{\mathrm{aq}}(36 \%$, $3 \mathrm{~mL})$ in $\mathrm{H}_{2} \mathrm{O}(100 \mathrm{~mL})$ was added, and the reaction mixture was stirred for $3 \mathrm{~h}$ at room temperature. The reaction mixture was washed with water and organic layer extracted with $\mathrm{CHCl}_{3}$, dried over $\mathrm{Na}_{2} \mathrm{SO}_{4}$ and diluted the solution to $300 \mathrm{~mL}$ with $\mathrm{CHCl}_{3}$. To this, p-Chloranil $(0.45 \mathrm{~g}, 1.83 \mathrm{mmol})$ was added and the reaction mixture was refluxed for $1 \mathrm{~h}$. The reaction mixture was passed in flash column chromatography using silica gel with $\mathrm{CHCl}_{3} /$ hexane $(1: 1 \mathrm{v} / \mathrm{v})$ as eluent ; recrystallization with $\mathrm{CHCl}_{3} /$ hexane afforded pure solid TPACor $2(0.42 \mathrm{gm}, 25 \%) .{ }^{1} \mathrm{H}$ NMR $\left(\mathrm{CDCl}_{3}\right) \delta \mathrm{ppm} 1.61$ (s, 36H), $7.13(\mathrm{~m}, 2 \mathrm{H}), 7.42(\mathrm{~m}, 10 \mathrm{H}), 7.75(\mathrm{~m}, 2 \mathrm{H}), 8.05$ $(\mathrm{m}, 2 \mathrm{H}), 8.25(\mathrm{~m}, 4 \mathrm{H}), 8.55-8.72(\mathrm{~d}, 4 \mathrm{H}), 8.82-9.01(\mathrm{~d}, 4 \mathrm{H})$; ESI-MS $[\mathrm{M}]^{+} \mathrm{m} / \mathrm{z}$ 919; Elemental Analysis: $\left(\mathrm{C}_{65} \mathrm{H}_{67} \mathrm{~N}_{5}\right) \mathrm{C}$, 85.02; H, 7.35; N, 7.63\%; UV-Vis $\left(\mathrm{CH}_{2} \mathrm{Cl}_{2}\right): \lambda_{\max } / \mathrm{nm}, 306$, $420,578,621,651$.

\subsubsection{0-triphenylamine-5,15-di(4-nitro)phenylcorrole}

(TPACor 3): We have adopted similar synthetic procedure as that of TPACor 2 by the reaction between 4(Diphenylamino) benzaldehyde (DPM 3) (1 gm, $3.66 \mathrm{mmol})$ with 5-(4-nitrophenyl)dipyrromethane (1.94 gm, $7.32 \mathrm{mmol})$ 
and p-Chloranil (0.45 g, $1.83 \mathrm{mmol})$. Purification by silica column chromatography $\left(\mathrm{CHCl}_{3} /\right.$ hexane, $\left.4: 6 \mathrm{v} / \mathrm{v}\right)$ and recrystallization with $\mathrm{CHCl}_{3} /$ hexane afforded pure solid TPACor $3(0.53 \mathrm{gm}, 36 \%)$. ${ }^{1} \mathrm{H}$ NMR $\left(\mathrm{CDCl}_{3}\right) \delta \mathrm{ppm} 7.15$ $(\mathrm{d}, 2 \mathrm{H}), 7.42(\mathrm{~m}, 10 \mathrm{H}), 8.08(\mathrm{~d}, 2 \mathrm{H}), 8.55(\mathrm{~d}, 4 \mathrm{H}), 8.62(\mathrm{~d}$, 2H), 8.70 (d, 4H), 8.79 (d, 2H), 8.88 (d, 2H), $9.1(\mathrm{~d}, 2 \mathrm{H})$; ESI-MS $[\mathrm{M}]^{+} \mathrm{m} / \mathrm{z}$ 785; Elemental Analysis: $\left(\mathrm{C}_{49} \mathrm{H}_{33} \mathrm{~N}_{7} \mathrm{O}_{4}\right)$ C, 75.08; $\mathrm{H}, 4.24 ; \mathrm{N}, 12.51 ; \mathrm{O}, 8.16 \%$. UV-Vis $\left(\mathrm{CH}_{2} \mathrm{Cl}_{2}\right)$ : $\lambda_{\max } / \mathrm{nm}, 309,448,596,657$.

\subsection{Methods and Instrumentation}

${ }^{1} \mathrm{H}$ NMR spectra were recorded on a $500 \mathrm{MHz}$ INOVA spectrometer. Cyclic and differential-pulse voltammetric measurements were performed on a PC-controlled electrochemical analyser (CH instruments model CHI620C). All these experiments were performed with $1 \mathrm{mM}$ concentration of compounds in dichloromethane at a scan rate of $100 \mathrm{mV} \mathrm{s}^{-1}$ in which tetrabutylammoniumperchlorate (TBAP) was used as a supporting electrolyte, standard calomel as reference electrode, glassy carbon as working electrode and Pt-wire as counter electrode. ${ }^{43}$

2.3.1 Absorption and fluorescence measurements: The optical absorption spectra were recorded on a Shimadzu (Model UV-3600) spectrophotometer. Concentrations of solutions are ca. $1 \times 10^{-6} \mathrm{M}$ (corrole Soret band) and 1 $\times 10^{-5} \mathrm{M}$ (corrole Q-band). Steady-state fluorescence spectra were recorded on a Fluorolog-3 spectrofluorometer (Spex model, JobinYvon) for solutions with optical density at the wavelength of excitation $\left(\lambda_{\text {ex }}\right) \approx 0.05$. Fluorescence quantum yields $(\Phi)$ were estimated by integrating the fluorescence bands and by using triphenylcorrole ( $\Phi=0.21$ in toluene) as reference compound. ${ }^{18}$ Fluorescence life-time measurements were carried on a picosecond time-correlated single photon counting (TCSPC) setup (FluoroLog3-Triple Illuminator, IBH Horiba JobinYvon) employing a picosecond light-emitting diode laser (NanoLED, $\lambda_{\mathrm{ex}}=405 \mathrm{~nm}$ ) as the excitation source. The decay curves were recorded by monitoring the fluorescence emission maxima of the dyad $\left(\lambda_{\mathrm{em}}=\right.$ $675 \mathrm{~nm}$ ). A photomultiplier tube (R928P, Hamamatsu) was employed as the detector. The lamp profile was recorded by placing a scatterer (dilute solution of Ludox in water) in place of the sample. The width of the instrument response function (IRF) was limited by the full-width at half-maximum (FWHM) of the excitation source, $\sim 625 \mathrm{ps}$ at $405 \mathrm{~nm}$. Decay curves were analysed by nonlinear least-squares iteration procedure using IBH DAS6 (version 2.3) decay analysis software. The quality of the fits was judged by the $\chi^{2}$ values and distribution of the residuals.

2.3.2 Computational studies: All the theoretical calculations have been performed by using a Gaussian 09 package ${ }^{44}$ on personal computer. The obtained geometries of all the three dyads TPACor 1, TPACor 2, and TPACor 3 were stable in their conformation to genuine global minimum structures using B3LYP hybrid functional ${ }^{45}$ and 6-31G(d,p) basis $\operatorname{set}^{46}$ and used as the input for further calculations. Ground state properties, frontier molecular orbitals (FMOs) and electrostatic potential maps (ESP) were calculated for energy minimized structures by density functional theory (DFT) in the gas phase.

Excited state properties like percentage of molecular contribution, oscillatory strength, singlet transition energy were obtained by time-dependent density functional theory (TDDFT) in acetonitrile solvent. The geometries were then used to obtain the frontier molecular orbitals (FMOs) and single-point TDDFT studies (first 15 vertical singlet-singlet transitions) were also done to get the UV-Vis spectra of the dyads. The integral equation formalism polarizable continuum model (PCM) ${ }^{47,48}$ within the self-consistent reaction field (SCRF) theory was used in the TDDFT calculations to describe the solvation of the dyes in dichloromethane. ${ }^{47,48}$ The software GaussSum 2.2.5 was employed to interpret the nature of transitions and to simulate the major portions of the absorption spectra. ${ }^{49,50}$ The respective molecular orbitals were calculated by percentage contributions of individual units present in the dyads.

\section{Results and Discussion}

Triphenylamine based $\mathrm{A}_{2} \mathrm{~B}$-corrole dyads comprise of electron donating and withdrawing groups (phenyl or 3,5-di-tert-butylphenyl or 4-nitrophenyl) at $5^{\text {th }}$ and $15^{\text {th }}$ -meso positions of TPACor 1, TPACor 2 and TPACor 3, as shown in Chart 1. Synthesized by the condensation of 5-(3,5-ditertbutylphenyl)dipyrromethane (DPM 2), or 5-(4-nitrophenyl)dipyrromethane (DPM 3) with 4-(Diphenylamino)benzaldehyde (TPA-CHO) in the presence of water/methanol method ${ }^{17}$ (Gryko approach) as per the Scheme 1. DPM 1 and TPACor 1 have been synthesized as per our previous report. ${ }^{21}$ Preliminary characterization of these dyads were carried out by ${ }^{1} \mathrm{H}$ NMR and ESI-MS. The elemental analyses gave satisfactory results, which are presented in the experimental section. The ESI-MS spectrum of TPACor 2 and TPACor 3 displayed a peak at $\mathrm{m} / \mathrm{z}=919\left(\mathrm{C}_{65} \mathrm{H}_{67} \mathrm{~N}_{5}\right)$ and at $785\left(\mathrm{C}_{49} \mathrm{H}_{33} \mathrm{~N}_{7} \mathrm{O}_{4}\right)$ ascribable to the molecular ion peak. (Figures S3 and S4 in Supplementary Information). ${ }^{1} \mathrm{H}$ NMR spectral data of both TPACor 2 and TPACor $\mathbf{3}$ are described in experimental section, it is clearly shown that peaks in the aromatic region ( 7.0 to $9.5 \mathrm{ppm}$ ) consisting of both corrole and triphenylamine moieties. The intensive peak at $1.6 \mathrm{ppm}$ is responsible for methyl protons for TPACor 2 and no peak was observed for TPACor 3 (Figures S1 and S3 in Supplementary Information). 


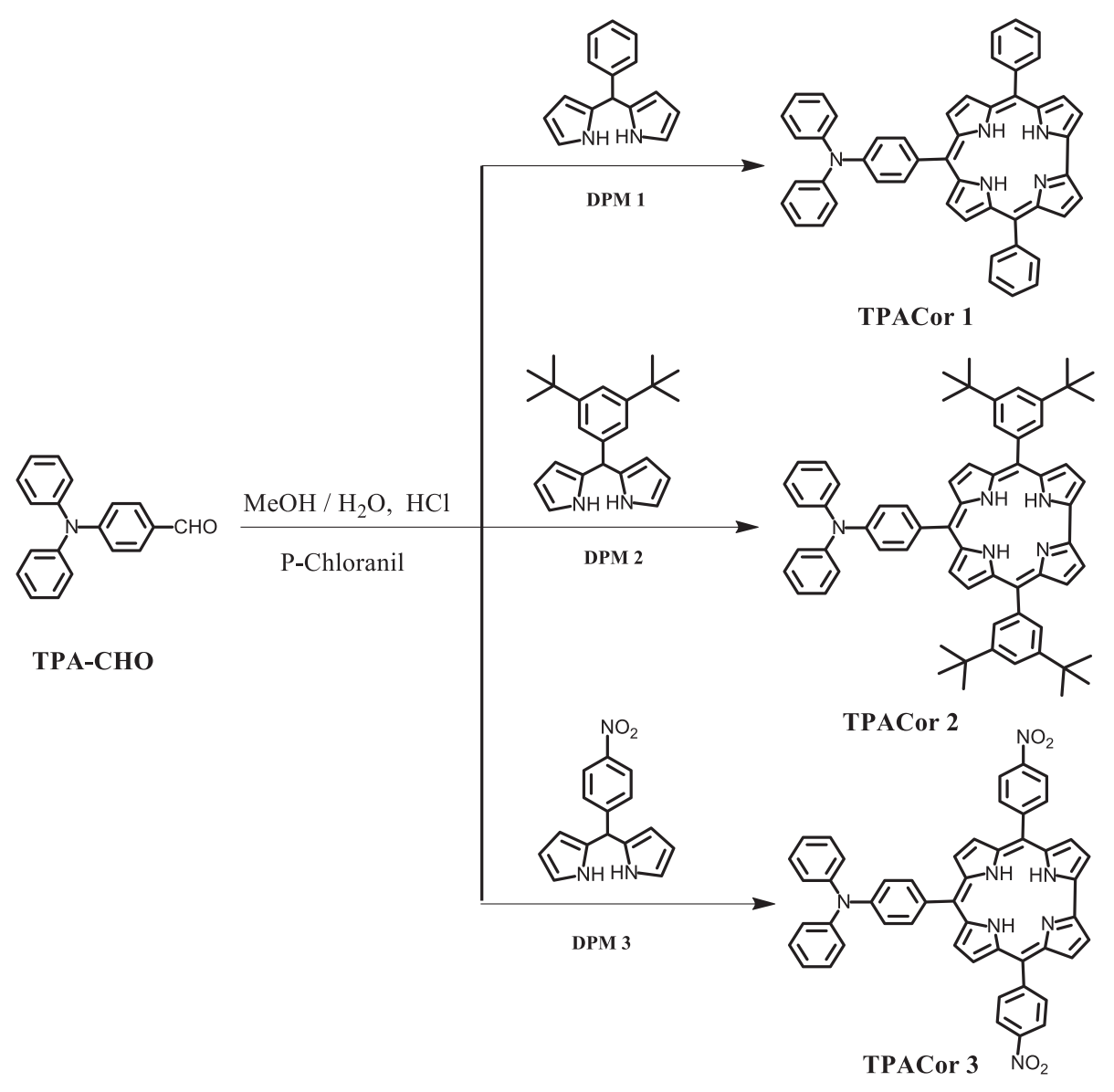

Scheme 1. The synthetic scheme of TPACor 1, TPACor 2 and TPACor 3 dyads.

\subsection{Absorption properties}

The electronic absorption spectra of the dyads along with their individual constituents are depicted in Figure 1 and the corresponding absorption maxima $\left(\lambda_{\max }\right)$ and molar extinction coefficients $(\varepsilon)$ are presented in Table 1. TPA and Soret band of TPC show absorption maxima $\left(\lambda_{\max }\right)$ at $300 \mathrm{~nm}$ and $414 \mathrm{~nm}$, respectively, due to $\pi-\pi$ electronic transitions. However, TPC has the minimum absorption at $300 \mathrm{~nm}$ (Figure 1) which is $~ 60 \%$ of TPA absorption intensity. In general, absorption spectra of corroles exhibit broad Soret and Q bands and lower intensity compared to porphyrins due to reduction in symmetry from $\mathrm{D}_{4 \mathrm{~h}}$ to $\mathrm{C}_{2 \mathrm{v}} \cdot{ }^{51}$ Both the Soret and Q bands of TPACor 1 and TPACor 2 are more or less similar to their individual components of TPA and TPC. In contrast, the nitro group $\left(-\mathrm{NO}_{2}\right)$ substituted corrole TPACor 3 has shown the following changes in the absorption spectra: (a) a red shift in Soret $(34 \mathrm{~nm})$ and Q bands (7 nm); (b) broadening and splitting of the Soret band $(\sim 30 \mathrm{~nm})$. The broadening and split in Soret band are probably due to the presence of electron withdrawing $-\mathrm{NO}_{2}$ group at peripheral positions of corrole macrocycle. ${ }^{34-38}$ The comparison of UV-Visible spectrum of both dyads with

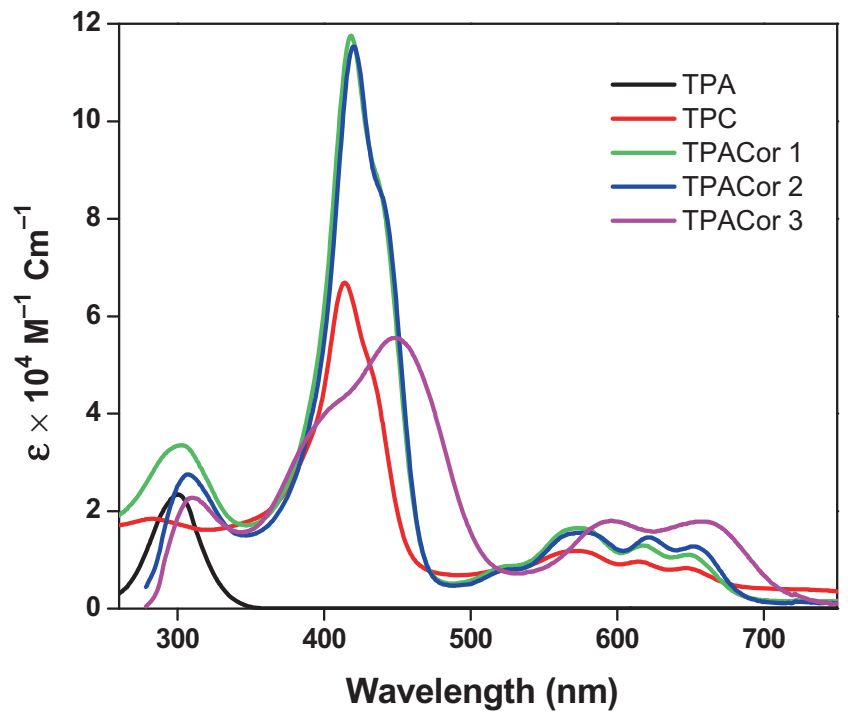

Figure 1. Absorption spectra of TPA, TPC, TPACor 1, TPACor 2, and TPACor 3 in $\mathrm{CH}_{2} \mathrm{Cl}_{2}$.

the corresponding precursor components suggests that the absorption data indicate minimum $\pi-\pi$ interaction between the components.

In general, the absorption properties of corroles are solvent dependent. To investigate this property, we have 
Table 1. Absorption and redox potential data.

\begin{tabular}{|c|c|c|c|c|c|c|c|c|c|c|c|c|c|}
\hline \multicolumn{6}{|c|}{ Absorption data $^{a} \lambda_{\max }, \mathrm{nm}\left(\varepsilon \times 10^{4}, \mathrm{M}^{-1} \mathrm{~cm}^{-1}\right)$} & \multicolumn{8}{|c|}{ Potential V vs SCE $\mathrm{S}^{\mathrm{b}}$} \\
\hline \multirow{2}{*}{$\frac{\text { Compound }}{\text { TPA }}$} & \multirow{2}{*}{$\frac{\text { TPA }}{300(2.32)}$} & \multicolumn{4}{|c|}{ Corrole } & \multicolumn{4}{|c|}{ Oxidation } & \multicolumn{4}{|c|}{ Reduction } \\
\hline & & - & - & - & - & 0.66 & 0.96 & - & - & - & - & - & - \\
\hline TPC & - & $414(6.71)$ & 71(1.19) & $614(0.97)$ & $647(0.8$ & 0.58 & 0.97 & 1.48 & - & - & -1.35 & -1.73 & - \\
\hline TPACor 1 & $300(3.38)$ & $417(11.7)$ & $572(1.39)$ & $617(1.1($ & $648(0.9$ & 0.53 & 0.85 & 1.15 & 1.63 & - & -1.48 & - & -1.96 \\
\hline TPACor 2 & $306(2.75)$ & $420(11.53)$ & $578(1.69)$ & $622(1.58)$ & $652(1.37)$ & 0.45 & 0.75 & 1.16 & 1.64 & - & -1.19 & - & -1.98 \\
\hline TPACor 3 & $309(2.27)$ & $448(5.54)$ & $596(2.02)$ & $655(1.96)$ & - & 0.62 & 0.89 & 1.19 & 1.82 & -0.92 & -1.12 & -1.60 & -2.1 \\
\hline
\end{tabular}

${ }^{a}$ Solvent $\mathrm{CH}_{2} \mathrm{Cl}_{2}$, Error limits: $\lambda_{\max }, \pm 1 \mathrm{~nm}, \log \varepsilon, \pm 10 \% .{ }^{\mathrm{b}} \mathrm{CH}_{2} \mathrm{Cl}_{2}, 0.1 \mathrm{M}$ TBAP; Glassy carbon is working electrode, Standard calomel electrode is reference electrode, Pt electrode is counter electrode. Error limits, $\mathrm{E}_{1 / 2} \pm 0.03 \mathrm{~V}$.

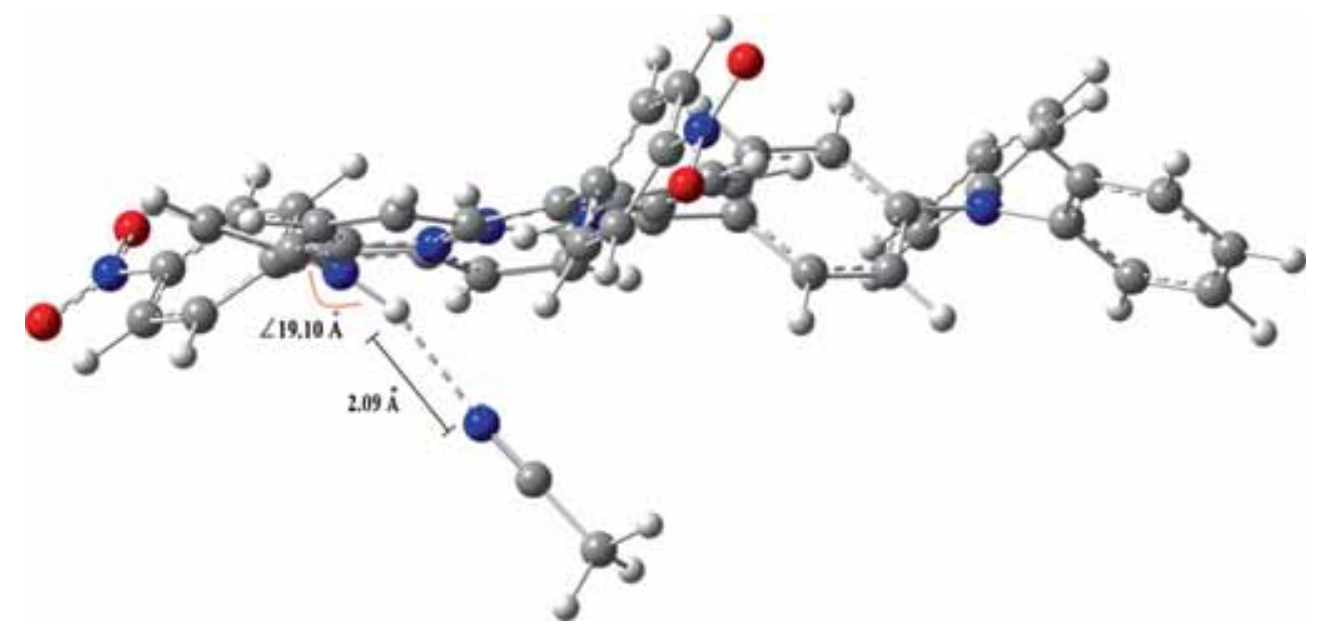

Figure 2. Optimized structure of TPACor 3 and acetonitrile by B3LYP and 6-31G(d,p) method.

carried out absorption studies of TPACor 1, TPACor 2 and TPACor 3 in non-polar (cyclohexane, toluene) and polar (dichloromethane and acetonitrile) solvents (Figure S5 in Supplementary Information). Spectra of TPACor 1 and TPACor 2 were more or less similar in all solvents except for small changes in acetonitrile. In contrast, the absorption spectrum of TPACor 3 differs from other dyads in all the solvents, particularly in the polar solvents. Predictable hydrogen bonding between the inner $\mathrm{N}-\mathrm{H}$ group of corrole with acetonitrile molecule was observed. Hydrogen attached to inner nitrogen is found to be bent w.r.t. corrole ring plane by $19.10^{\circ}$ towards acetonitrile molecule (Figure 2) and the bond length between $\mathrm{N}-\mathrm{H}$ and $\mathrm{N}-\mathrm{C}$ of acetonitrile is $2.09 \AA$. This is observed in the optimized minimum energy structure in acetonitrile, as shown in Figure 2. However, we failed to get the crystal of TPACor 3. This phenomenon was further supported by Ziegler in the previous finding in the X-ray structure of perfluorophenyl corrole, ${ }^{52}$ isolated from ethyl acetate.

\subsection{Electrochemical properties}

Figure 3 illustrates the differential pulse voltammograms of the newly designed D-A systems. Table 1 summarises the redox potential data (in $\mathrm{CH}_{2} \mathrm{Cl}_{2}$ and $0.1 \mathrm{M}$ TBAP) of the D-A systems investigated in this study along with those corresponding to individual constituents. From the Figure 3 and Table 1, one can deduce that each new dyad showed two reduction peaks and four oxidation peaks. Wave analysis suggested that, in general, the first two reduction steps and first three oxidation steps are reversible $\left(i_{p c} / i_{p a}=0.9-\right.$ $1.0)$ and diffusion-controlled $\left(i_{p c} / v^{1 / 2}=\right.$ constant in the scan rate $(v)$ range $50-500 \mathrm{mV} / \mathrm{s}$ ) one-electron transfer $\left(\Delta E_{p}=60-70 \mathrm{mV} ; \Delta E_{p}=65 \pm 3 \mathrm{mV}\right.$ for ferrocenium/ferrocene couple) reactions. The subsequent steps are, in general, either quasi- reversible $\left(\mathrm{E}_{\mathrm{pa}}-\mathrm{E}_{\mathrm{pc}}=90\right.$ $200 \mathrm{mV}$ and $i_{p c} / i_{p a}=0.5-0.8$ in the scan rate $(v)$ range $100-500 \mathrm{mV} \mathrm{s}^{-1}$ ). The reduction peaks solely belong to corrole macrocycle as TPA does not show any reduction under our experimental conditions. In contrast, first two oxidation peaks of the dyads belong to both corrole and TPA. Both oxidation and reduction peaks are shifted in the case of TPACor 3 due to the presence of electron withdrawing $-\mathrm{NO}_{2}$ group, as in the case of previously reported for $\beta$-nitro corrole. ${ }^{53}$

The spectroscopic and electrochemical data illustrate that electronic communication between corrole and TPA chromophores is quite negligible in these 


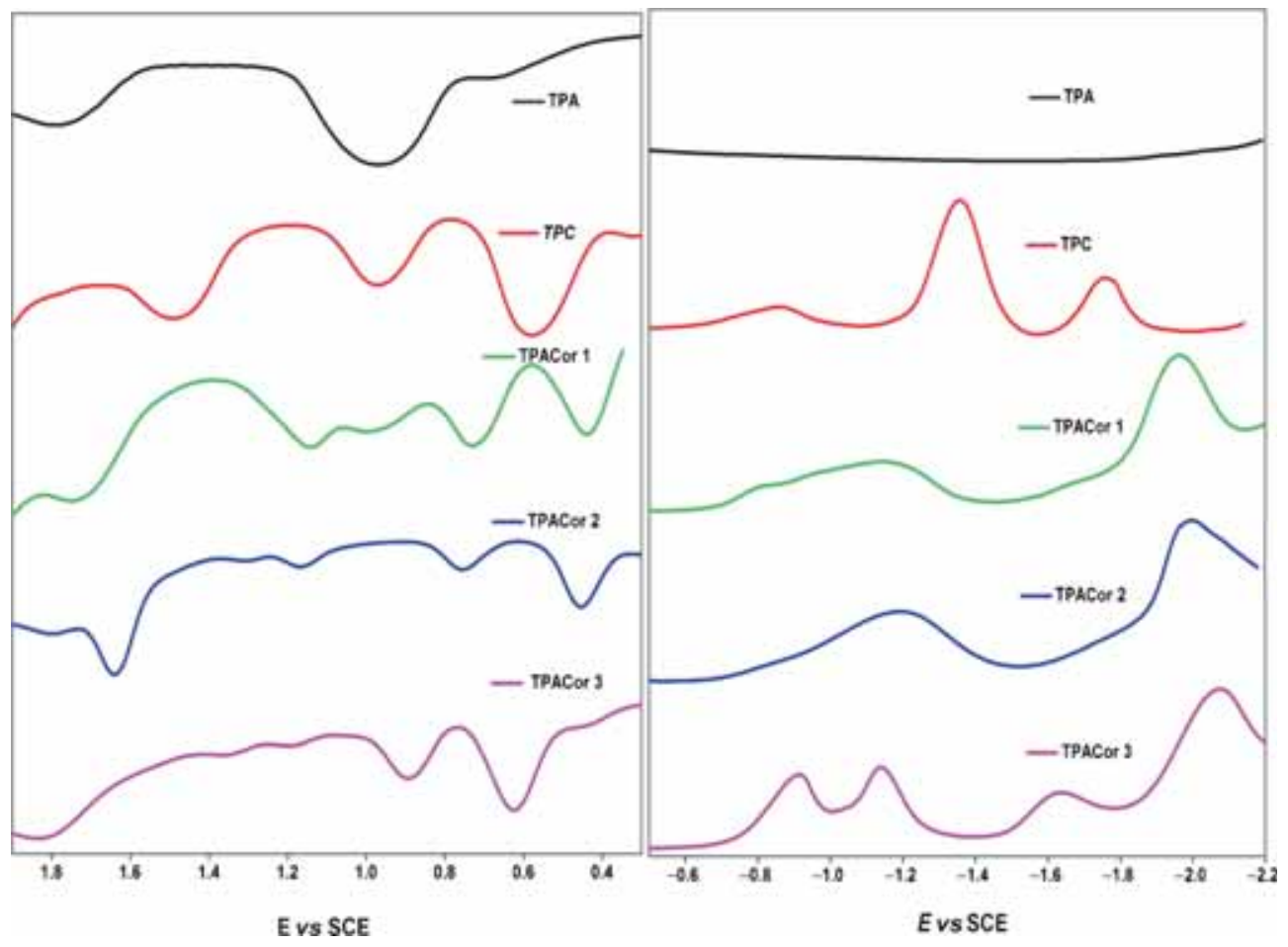

Figure 3. Differential pulse voltammograms in $\mathrm{CH}_{2} \mathrm{Cl}_{2}$ and $0.1 \mathrm{M} \mathrm{TBAP}$.

D-A systems. However, one can evalute the excited state properties by selective excitation of the individual chromophore units.

\subsection{Fluorescence properties}

The steady-state fluorescence spectra of all three dyads (TPACor 1, TPACor 2, and TPACor 3) and its constituent components (TPA and TPC) were characterized by strong emission bands in cyclohexane, toluene, $\mathrm{CH}_{2} \mathrm{Cl}_{2}$ and acetonitrile solvents. Remarkable differences have been observed between ground state and singlet state activities in these dyads, when compared to the monomeric units, TPA and TPC.

When excited at $300 \mathrm{~nm}$ where light is absorbed equally (50\%) TPA and corrole, quenched emission spectra were observed for all three dyads, when compared to isolated TPA. Figure 4 illustrates the emission spectra of dyads and TPA in cyclohexane and dichloromethane solvent. The corresponding singlet state data are presented in Table 2. Similar quenched emission spectra were also observed in toluene and acetonitrile
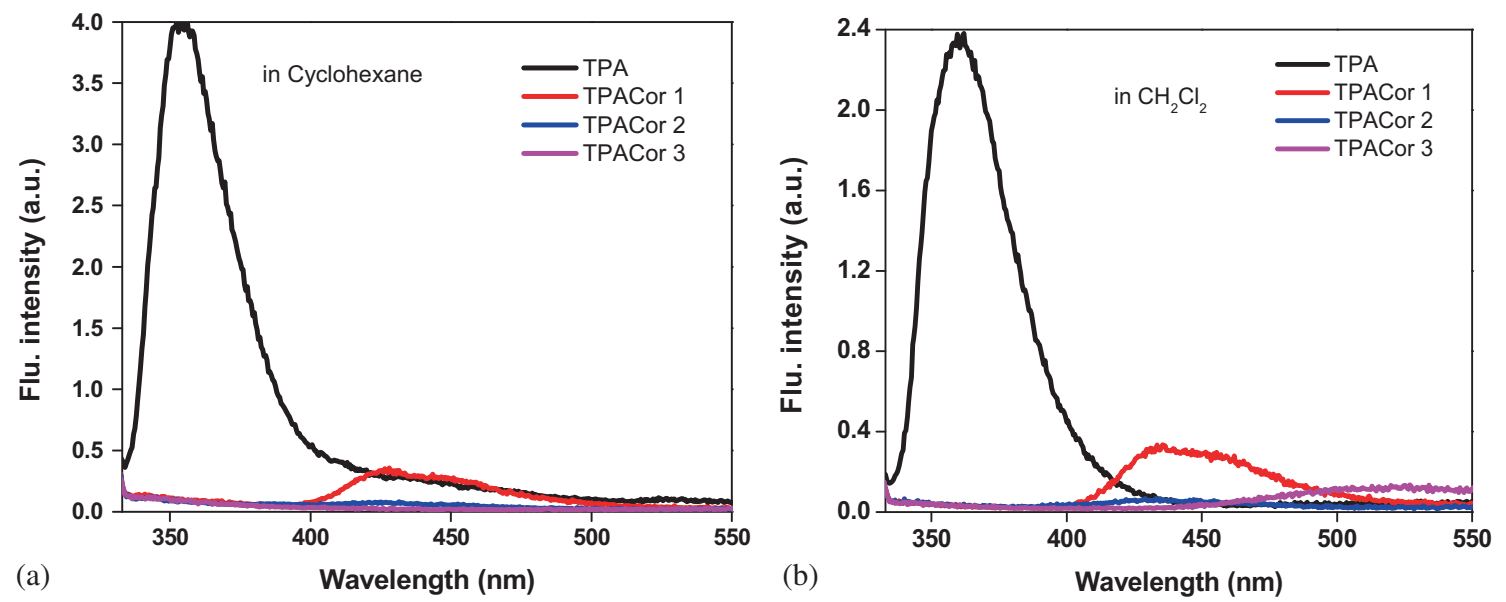

Figure 4. Fluorescence spectra $\left(\lambda_{\mathrm{ex}}=300 \mathrm{~nm}\right)$ and $\left(\mathrm{OD}\right.$ at $\left.\lambda_{\mathrm{ex}}=0.05\right)$ of equally absorbing solutions of TPA, TPACor 1,TPACor 2 and TPACor 3 in (a) cyclohexane, (b) $\mathrm{CH}_{2} \mathrm{Cl}_{2}$. 


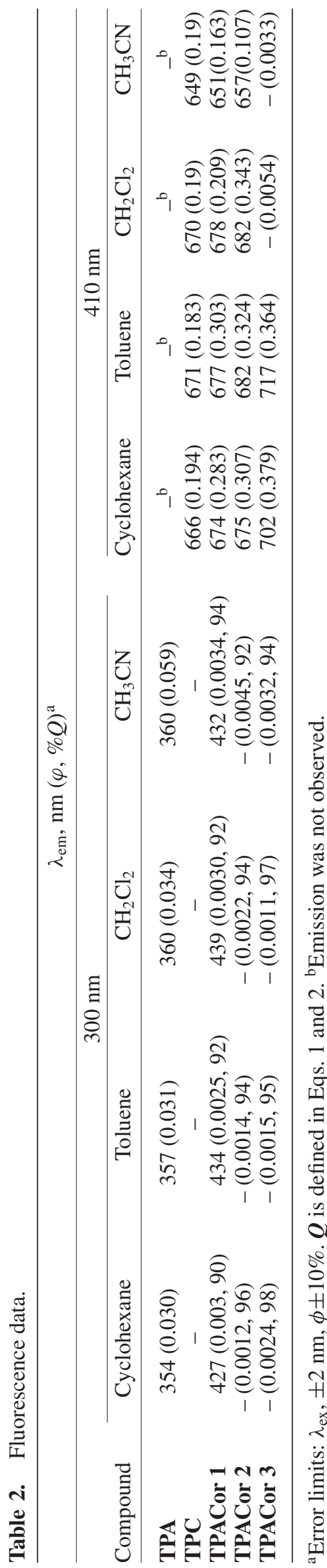

solvents (Figure S6 in Supplementary Information). However, for selective excitation at $410 \mathrm{~nm}$ i.e., the $\lambda_{\max }$ corresponding to the corrole absorption maximum, the resulted spectra are seen to be similar to that of the spectrum of TPC in all the investigated solvents, except the dyad TPACor 3 (Figure 5). The emission maxima of all three dyads are red-shifted when compared to emission maxima of TPC. In case of TPACor 3 the emission maximum is further red shifted, when compared to TPC. More interestingly, unquenched emission spectra were observed in non-polar solvents (cyclohexane and toluene) while in the case of polar solvents, $\mathrm{CH}_{2} \mathrm{Cl}_{2}$ and acetonitrile, quenching of emission ( $\left.\sim 97 \%\right)$ was observed as shown in Figure 5 and Figure S7 (Supplementary Information) and the corresponding data are presented in Table 2. This might be due to the presence of electron withdrawing $-\mathrm{NO}_{2}$ group, which stabilizes the excited state in polar solvents. Also, the formation of a hydrogen bond with inner $\mathrm{N}-\mathrm{H}$ group that leads to a tendency for charge-transfer in the excited state, an effect which is more pronounced in polar solvents.

Observed differences in fluorescence data between the dyads and TPC and TPA are seen in the magnitude of $\Phi_{\mathrm{f}}$ values (Table 2). Whereas quantum yield $\Phi_{\mathrm{f}}$ for excitation of the corrole moiety was slightly higher than that of TPC $\left(\lambda_{\text {ex }}=410 \mathrm{~nm}\right): \Phi_{\mathrm{f}}=0.16-0.30$ for TPACor 1 and $\Phi_{\mathrm{f}}=0.10-0.34$ for TPACor 2 in non-polar and polar solvents. In contrast, quantum yield values of TPACor 3 are low (strongly quenched) in polar solvents, when compared to TPC (Table 2). However, fluorescence of all the three dyads from the triphenylamine part of the dyads is strongly quenched in comparison with the fluorescence of TPA in all the four investigated solvents. The quenching efficiency $\mathrm{Q}$ can be calculated as follows:

$$
Q=\frac{\phi(T P A)-\phi((T P A \operatorname{Cor} 1(\text { or }) T P A C o r 2(\text { or }) T P A C o r 3)}{\phi(T P A)}
$$

(or)

$$
Q=\frac{\phi(T P C)-\phi(T P A C o r 3)}{\phi(T P C)}
$$

and $\mathrm{k}_{\mathrm{obs}}$ (observed rate of quenching),

$$
k_{o b s}=\frac{Q /(1-Q)}{\tau(T P A)}
$$

$\mathrm{Q}$ and $\mathrm{k}_{\mathrm{obs}}$ values are are given in Table 2. In equation 1, $\Phi($ TPA) and $\Phi(($ TPACor 1, TPACor $\mathbf{2}$ or TPACor 3) refer to the fluorescence quantum yields for triphenylamine and the dyads $\left(\lambda_{\mathrm{ex}}=300 \mathrm{~nm}\right)$, respectively. In equation 2, $\Phi($ TPC) and $\Phi(($ TPACor $3)$ refer to the fluorescence quantum yields of corrole and dyad TPACor $3\left(\lambda_{\text {ex }}=410 \mathrm{~nm}\right)$, respectively. In equation $3, \tau$ (TPA) is the singlet-state lifetime of 

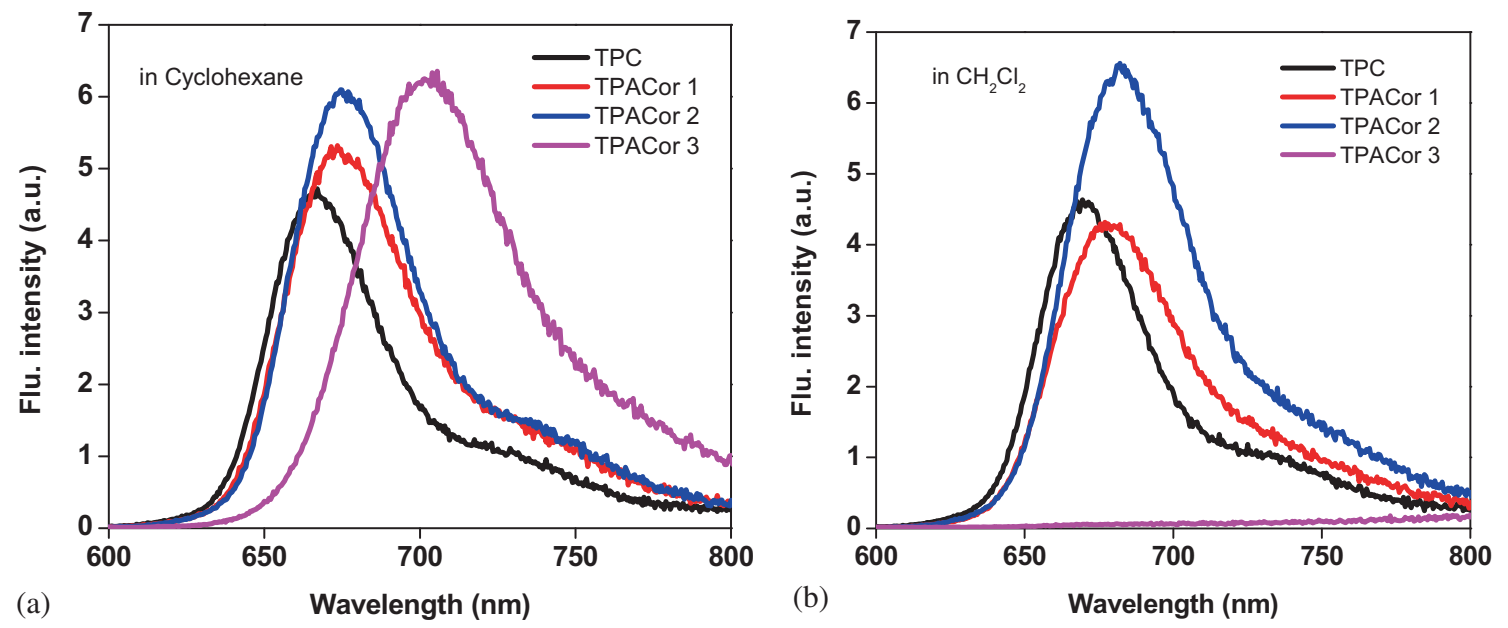

Figure 5. Fluorescence spectra $\left(\lambda_{\mathrm{ex}}=410 \mathrm{~nm}\right)$ and (OD at $\left.\lambda_{\mathrm{ex}}=0.05\right)$ of equally absorbing solutions of TPC, TPACor 1, TPACor 2 and TPACor 3 in (a) cyclohexane, (b) $\mathrm{CH}_{2} \mathrm{Cl}_{2}$.

triphenylamine $2.23 \mathrm{~ns}, 3.36 \mathrm{~ns}, 1.02 \mathrm{~ns}$, and $1.97 \mathrm{~ns}$, in cyclohexane, toluene, $\mathrm{CH}_{2} \mathrm{Cl}_{2}$, and $\mathrm{CH}_{3} \mathrm{CN}$, respectively (Figure S9, in Supplementary Information). On the other hand, singlet-state lifetime of dyads TPACor $\mathbf{1}$ and TPACor $\mathbf{2}$ are similar when compared to TPC $\left(\lambda_{\mathrm{ex}}=410 \mathrm{~nm}\right)$ and quenched decay curves are observed for dyad TPACor $\mathbf{3}$ inpolar solvents (Figure $\mathrm{S} 8$ in Supplementary Information). The $\mathrm{E}_{0-0}$ values of the TPA $(3.75 \pm 0.05 \mathrm{eV})$ and the corrole $(1.88 \pm 0.05 \mathrm{eV}$ for TPC) moieties of these dyads, estimated from the overlap of their absorption and emission spectra (Figure S14 in Supplementary Information), were found to be in the similar range as the $\mathrm{E}_{0-0}$ values of TPA and TPC, respectively.

The strong quenching of emission intensity of all the three dyads irrespective of substituents, when excited at $300 \mathrm{~nm}$ is probably due to either excited state energy transfer (EET) or photoinduced electron transfer (PET). As evident from Figures 1 and 5, the emission spectrum of triphenylamine overlaps with the absorption spectra of corrole in all three dyads, this suggests that quenching of the fluorescence of triphenylamine in these D-A systems can be due to an intramolecular energy transfer from the singlet state of triphenylamine to the ground state corrole, as proved in our previous case (TPACor 1). ${ }^{21}$ The situation is similar in other two dyads TPACor 2 and TPACor 3. Excitation of approximately $10^{-7} \mathrm{M}$ solution of dyads, at $300 \mathrm{~nm}$ resulted in the appearance of well-defined corrole emission bands in both polar and non-polar solvents, except in polar solvents (DCM and acetonitrile) in the case of TPACor 3 dyad, where corrole emission was not observed. This might be due to the charge transfer occurring between polar solvent and inner $\mathrm{N}-\mathrm{H}$ of corrole macrocycle by the hydrogen bonding. ${ }^{52}$ Furthermore, when the fluorescence was monitored at the corrole emission maximum $\left(\lambda_{\mathrm{em}}=680 \mathrm{~nm}\right)$, the excitation spectrum taken for all three dyads showed bands characteristic of triphenylamine absorption except the dyad TPACor 3 in polar solvents (Figure 6). All these observations are indicating that in these bichromophoric systems the energy transfer is intramolecular rather than intermolecular.

\subsection{Photoinduced reactions}

Energy transfer efficiencies $\mathrm{T}_{\mathrm{obs}}$ were calculated by overlapping of normalized excitation spectra with the corresponding absorption spectra (Figure 6) of all three dyads in the investigated solvents. ${ }^{54}$ The calculated values of efficiency of energy transfer $(\% \mathrm{~T})$ and the rate of energy transfer $\left(\mathrm{K}_{\mathrm{EN}}\right)$ are given in Table $4 . \mathrm{K}_{\mathrm{EN}}$ was calculated from Eq. 4.

$$
k_{E N}(o b s)=\frac{T_{o b s} /\left(1-T_{o b s}\right)}{\tau(T P A)}
$$

Now we shall try to arrive at a mechanistic interpretation of the EET as well as the influence of substituents and solvents on energy transfer in these dyads by employing the obtained data.

In bichromophoric D-A systems energy transfer reactions can proceed mainly through two types of mechanism, ${ }^{55}$ i.e., Forster mechanism (dipole-dipole interaction) ${ }^{56}$ and Dexter mechanism (quantum mechanical exchange) ${ }^{57}$ Both the Forster and the Dexter mechanisms require that the rate of energy transfer be proportional to spectral overlap $\mathrm{J}$ of the donor emission and the acceptor absorption. Overlap integral $\mathbf{J}_{\text {Forster }}$ (Eq. 5) for all three dyads in the investigated solvents were found to be $2.39 \pm 0.02 \times 10^{-16} \mathrm{M}^{-1} \mathrm{~cm}^{3}$ and in 

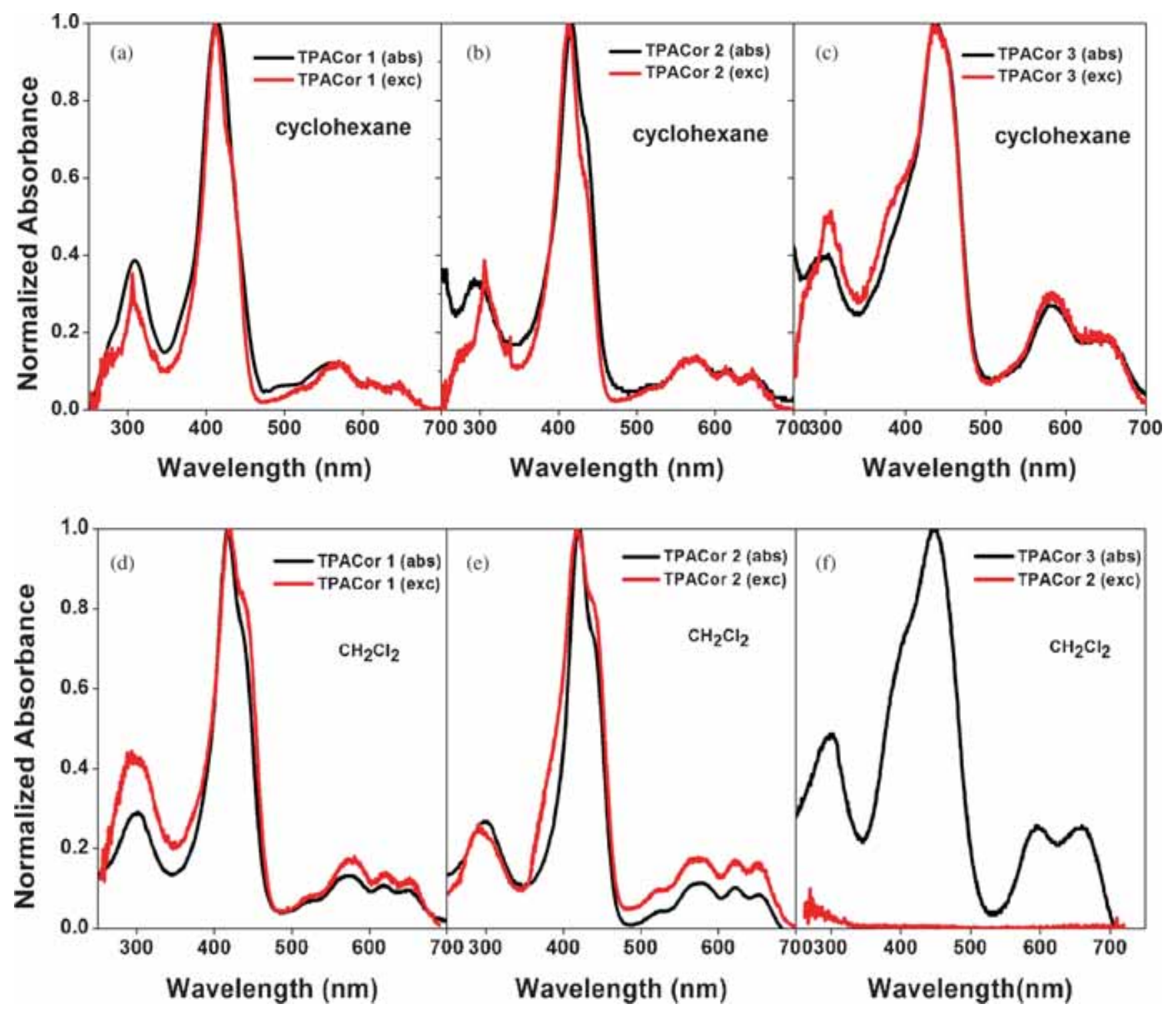

Figure 6. Overlay of the absorption (-) and excitation (-) spectra of TPACor 1, TPACor 2 and TPACor 3 in (a, b, c) cyclohexane, (d, e, f) $\mathrm{CH}_{2} \mathrm{Cl}_{2}$ solvents at corrole emission $\lambda_{\max }$. The excitation spectra were corrected for the instrument response function and were normalized with respect to the absorption spectra as described in ref. ${ }^{54}$

this case, no direct correlation of these integrals could be made with the $\mathrm{k}_{\mathrm{EN}}(\mathrm{obs})$ (or $\mathrm{T}_{\mathrm{obs}}$ ) values.

$$
J_{\text {Forster }}=\int_{0}^{\infty} F_{D}(\lambda) \varepsilon_{A}(\lambda) \lambda^{4} d \lambda
$$

$(\mathrm{F}(\lambda)$ is the normalized fluorescence intensity of the energy donor at wavelength $\lambda(\mathrm{cm})$, and $\varepsilon\left(\mathrm{M}^{-1} \mathrm{~cm}^{-1}\right)$ is the molar extinction coefficient of energy acceptor). The rate constant $\mathrm{k}_{\text {Forster }}$ for the Forster mechanism is calculated as follows. ${ }^{58}$

$$
k_{\text {Forster }}=\frac{9000 \ln 10 \phi_{D} \kappa^{2} J_{\text {Forster }}}{128 \pi^{5} N_{A} n^{4} \tau_{D} R^{6}}
$$

Where $\mathrm{n}$ is the solvent refractive index, $\Phi_{\mathrm{D}}$ and $\tau$ are the fluorescence quantum yield and lifetime of the isolated donor, $\kappa^{2}$ is an orientation factor that takes into account the relative orientation of the transition dipole moments of the donor and the acceptor, which can be simplified to the statistical value, $2 / 3$ and $R=8.69 \AA$ is the donoracceptor center-to-center distance for all three dyads. It is clear from Table 3, that the $\mathrm{k}_{\mathrm{EN}}$ (obs) values do not show a good correlation with the $\mathrm{k}_{\text {Forster }}$ values calculated for EET. Accordinglly, these observations clearly suggest that the energy transfer rates in this D-A system are inadequately explained by the Forster mechanism, as is the case with the 1,8-naphthalimide-corrole dyads in our previous dyad TPACor $\mathbf{1}^{21,59}$

In contrast, Dexter mechanism for the energy transfer in these dyads is specified by arguments based on D-A distance (DFT-B3LYP method using 6-31G(d,p)) and thermodynamic (redox) data. The estimated edge- 


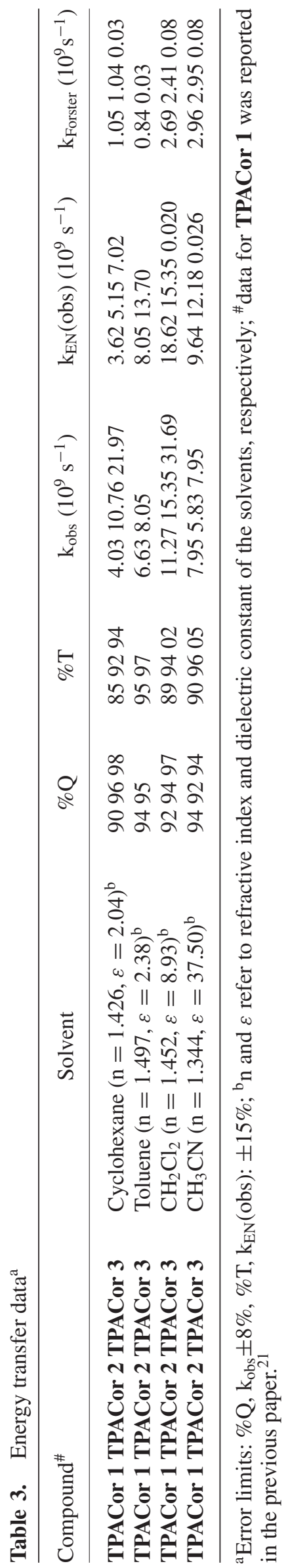

to-edge approach distance ( $\mathrm{Re}$ ) between triphenylamine and the corrole is $1.493 \AA$. This Re distance may facilitate D-A orbital interactions and promote electron exchange process. In addition, Dexter's mechanism involves both the highest occupied molecular orbital (HOMO) and lowest unoccupied molecular orbital (LUMO) of D and A, and electron exchange can occur in either a stepwise or concerted process via electron transfer reactions involving radical intermediates of the type $\mathrm{D}^{+} \mathrm{A}^{-}$and $\mathrm{D}^{-} \mathrm{A}^{+}$. For this event, the HOMO and LUMO of the acceptor must be either iso-energetic with or sandwiched between the levels of the HOMO and the LUMO of the donor. ${ }^{60}$ The latter situation holds good for the dyads as it can be seen that the corrole energy levels $\left(\mathrm{Cor}^{+}\right.$and $\left.\mathrm{Cor}^{-}\right)$are sandwiched between those of triphenylamine (TPA and $\mathrm{TPA}^{-}$) and that electron exchange energy transfer from the singlet triphenylamine to the corrole subunit in these bichromophoric systems is possible on thermodynamic grounds (see Figure S17 in Supplementary Information). Thus, both the distance and thermodynamic criteria indicate the possibility of the involvement of electron exchange mediated energy transfer in these D-A systems. Nevertheless, we hope that generally it is not correct to consider exclusively a Forster or a Dexter mechanism for a singlet-singlet inter-chromophore energy transfer and that this is especially so for the bichromophoric D-A systems.

Furthermore, the photoinduced electron transfer reactions cannot be rule-out in these dyad systems. The change in free-energy for an electron transfer $\left(\Delta \mathrm{G}_{\mathrm{PET}}\right)$ from the singlet triphenylamine to the ground state of corrole in these systems, was calculated by employing the redox potential and $\mathrm{E}_{0-0}$ data, and Eq. 7 as follows.

$$
\Delta \mathrm{G}_{\mathrm{PET}}=\mathrm{E}_{1 / 2}\left(\mathrm{TPA}^{+} / \mathrm{TPA}\right)-\mathrm{E}_{1 / 2}\left(\mathrm{Cor} / \mathrm{Cor}^{-}\right)-\mathrm{E}_{0-0}-\mathrm{X}
$$

The term $X$ (eq. 8) takes into account the finite donoracceptor separation $\left(R_{C}\right)$, ionic radii $\left(\mathrm{r}^{+}, \mathrm{r}^{-}\right)$, the electron charge $e$, the permittivity of free space $\left(\varepsilon_{0}\right)$ (can take unity) and solvent dielectric constant $\left(\varepsilon_{s}\right)$ :

$$
X=\frac{e^{2}}{4 \pi \varepsilon_{0} \varepsilon_{S} R_{C}}+\frac{e^{2}}{8 \pi \varepsilon_{0}}\left(\frac{1}{r^{+}}+\frac{1}{r^{-}}\right)\left(\frac{1}{\varepsilon_{r e f}}-\frac{1}{\varepsilon_{S}}\right)
$$

The radius of the donor radical cation $\left(\mathrm{TPA}^{+}\right)$for all three dyads is $\mathrm{r}^{+}=4.23 \AA$. The acceptor radical anions $\left(\mathrm{Cor}^{-}\right)$for the three dyads are $\mathrm{r}^{-}=7.53 \AA$ for TPACor $1, \mathrm{r}^{-}=7.82 \AA$ for TPACor 2 and $\mathrm{r}^{-}=7.64 \AA$ for TPACor 3. The center-to-center distance between donoracceptor was found to be $8.69 \AA$ for all the three dyads, calculated from the energy minimization by using DFT. $\left(\mathrm{E}_{1 / 2}\left(\mathrm{TPA}^{+} / \mathrm{TPA}\right)\right.$ and $\mathrm{E}_{1 / 2}\left(\mathrm{Cor} / \mathrm{Cor}^{-}\right)$are the oxidation potential of triphenylamine and the reduction potential 
of the corrole, respectively, vide supra). $\Delta \mathrm{G}_{\mathrm{PET}}$ for TPACor 1 was found to be $-1.662,-1.734,-1.785$ and $-1.672 \pm 0.05 \mathrm{eV}$, for TPACor 2 was -1.733 , $-1.749,-1.796$ and $-1.745 \pm 0.05 \mathrm{eV}$. and TPACor 3 was $-1.732,-1.734,-1.797$ and $-1.745 \pm 0.05 \mathrm{eV}$ in solvents cyclohexane, toluene, $\mathrm{CH}_{2} \mathrm{Cl}_{2}$ and acetonitrile, respectively.

EET is the major pathway for the quenching of fluorescence of these dyads TAPCor 1 (>90\%) and TPACor $2(>94 \%)$ in both polar and non-polar solvents but one can not ruled out the possibility of PET reactions. The situation holds true even in the case of TPACor 3 in non-polar solvents, whereas in polar solvents the major pathway is PET reaction as it is evident from the energy transfer studies (Figure 6). As a whole, the substituents do not have much effect on photoinduced reactions of these dyad systems.

\subsection{Computational studies}

To gain deep understanding into the structural, electronic, and optical properties of the triphenylamine-corrole dyads with donating or releasing groups at 5,15-meso positions DFT and TDDFT calculations were carried out with a functional basis set of B3LYP/6-31G(d, p) level. Table 4 shows the ground state properties of energy-optimized structures, HOMO-LUMO pictures and the electrostatic potential (ESP) maps for the corrole dyads. In all three dyads, triphenylamine is common at $10^{\text {th }}$ position of corrole and 5,15-positions are varied by aryl groups i.e., phenyl, 3,5-diterbutylphenyl, and 4-nitrophenyl for TPACor 1, TPACor 2, and TPACor 3, respectively, for which minimum energy values are given in Table 5. The electron density distribution for the HOMO and LUMO of corrole

Table 4. The optimized structures, electron distributions in HOMO and LUMO and electrostatic potential map for TPACor 1, TPACor 2 and TPACor 3 dyads.

\begin{tabular}{|c|c|c|c|c|}
\hline Compound & Optimized Structure & HOMO & LUMO & Electrostatic potential map \\
\hline \multicolumn{5}{|l|}{ TPACor 1} \\
\hline \multicolumn{5}{|l|}{ TPACor 2} \\
\hline \multicolumn{5}{|l|}{ TPACor 3} \\
\hline
\end{tabular}

Table 5. Ground state data for TPACor 1, TPACor 2 and TPACor 3 with B3LYP/6-31G (d,p).

\begin{tabular}{lcccc}
\hline Compound & $\begin{array}{c}\text { Minimized energy } \\
\left(\mathrm{kcal} \times 10^{-18}\right)\end{array}$ & $\begin{array}{c}\text { HOMO } \\
\text { in }-\mathrm{eV}\end{array}$ & $\begin{array}{c}\text { LUMO } \\
\text { in }-\mathrm{eV}\end{array}$ & $\begin{array}{c}\text { HOMO-LUMO } \\
\text { gap in eV }\end{array}$ \\
\hline TPACor 1 & -2.250 & -4.52 & -2.09 & 2.43 \\
TPACor 2 & -2.908 & -4.44 & -2.02 & 2.42 \\
TPACor 3 & -2.678 & -5.00 & -2.86 & 2.14 \\
\hline
\end{tabular}


Table 6. Comparison of experimental absorption properties with Singlet excited state properties of all three dyads by B3LYP/6-31G $(\mathrm{d}, \mathrm{p})$ in dichloromethane solvent.

\begin{tabular}{lccccc}
\hline Compound & ${ }^{\mathrm{a}} \lambda_{\max }$ & ${ }^{\mathrm{b}} \lambda_{\max }$ & ${ }^{\mathrm{c}} f$ & ${ }^{\mathrm{d}} \mathrm{E}(\mathrm{eV})$ & \multicolumn{1}{c}{$\%$ of Molecular Orbital Contribution } \\
\hline TPACor 1 & 648 & 596 & 0.263 & 2.072 & $\begin{array}{l}\mathrm{H}-1 \rightarrow \mathrm{L}+1(13 \%), \mathrm{HOMO} \rightarrow \mathrm{LUMO}(81 \%) \\
\mathrm{H}-1 \rightarrow \text { LUMO }(2 \%), \mathrm{HOMO} \rightarrow \mathrm{L}+1(2 \%)\end{array}$ \\
TPACor 2 & 652 & 597 & 0.309 & 2.074 & $\begin{array}{l}\mathrm{H}-1 \rightarrow \mathrm{L}+1(13 \%), \mathrm{HOMO} \rightarrow \mathrm{LUMO}(81 \%) \\
\mathrm{H}-1 \rightarrow \mathrm{LUMO}(2 \%), \mathrm{HOMO} \rightarrow \mathrm{L}+1(2 \%)\end{array}$ \\
TPACor 3 & 655 & 664 & 0.440 & 1.866 & \begin{tabular}{l}
$\mathrm{HOMO} \rightarrow$ LUMO $(92 \%)$ \\
\hline
\end{tabular}
\end{tabular}

${ }^{a}$ Experimental absorbance in $\mathrm{nm},{ }^{\mathrm{b}}$ theoretical absorbance in $\mathrm{nm},{ }^{\mathrm{c}}$ Oscillation strength, and ${ }^{\mathrm{d}}$ excited state energy in $\mathrm{eV}$.
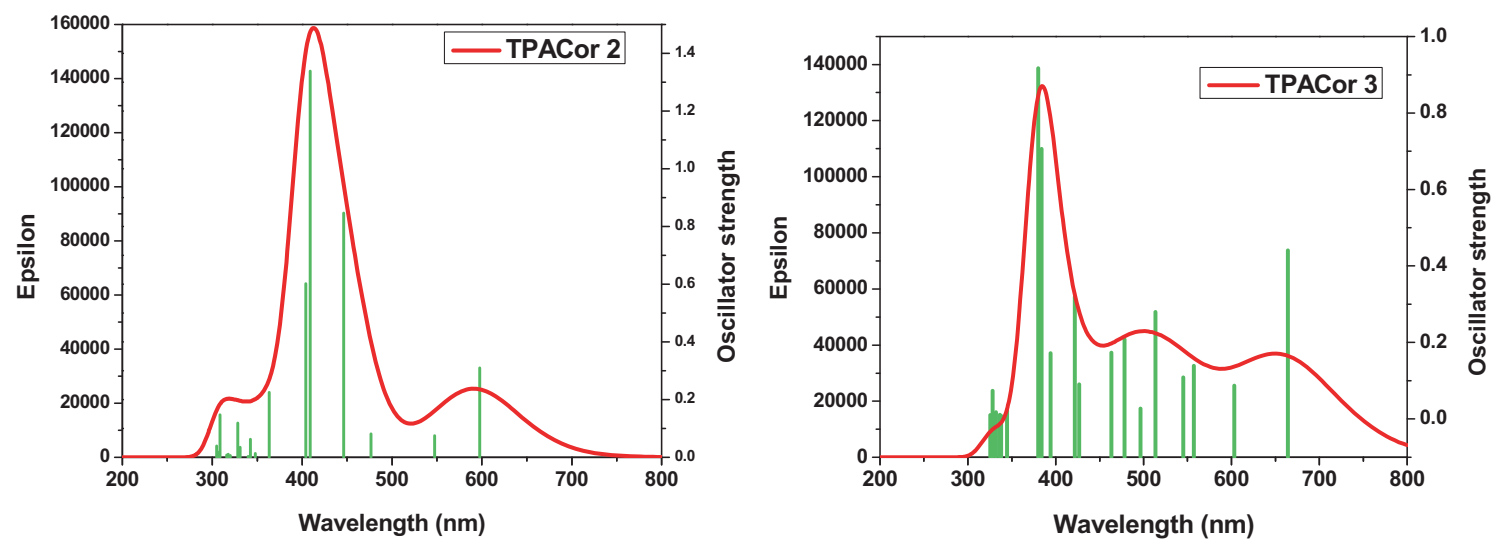

Figure 7. Theoretical absorption spectra of Dyads TPACor 2 and TPACor 3 in dichloromethane.

dyads TPACor 1 and TPACor 2 shows that HOMO is localized slightly on TPA and mostly on corrole ring, whereas LUMO is localized fully on corrole ring. In contrast, in TPACor 3 localization of HOMO is partially on both TPA and corrole ring, whereas LUMO is on slightly on corrole ring and mostly on nitrophenyl groups. Electrostatic potential maps of both TPACor 1 and TPACor 2 show greater electron charge distribution on one of the pyrroles of the corrole ring, while that of TPACor 3 shows at nitro group of meso phenyl ring. Accordingly, well-separated HOMO and LUMO levels indicate that charge transfer excitation occurs in these dyads. Table 5 shows the calculated HOMO-LUMO energy gap, found to be in the range of 2.14 to $2.43 \mathrm{eV}$ for the dyads. TPACor 3 shows the low energy gap and tendency to broad range of sunlight absorption.

Based on the experimental observations, TDDFT studies of these molecules were carried out using B3LYP energy functional with the 6-31G (d,p) basis set to gain a deeper insight of the excited-state transitions within the framework of the polarizable continuum model (PCM) in dichloromethane solvent. These results are in reasonable agreement with the experimental data. Table 6 shows singlet state properties of wavelength absorbance maximum, oscillation strength $(f)$, excited state energy (E) in $\mathrm{eV}$ and the percentage contribution of molecular orbital for all three dyads. Figure 7 shows absorption spectrum for each dyad segment computed from the frontier molecular orbitals by using the GaussSum software.

\section{Conclusions}

In conclusion, to study the effect of substituents on photophysical properties we have designed and synthesized D-A systems in which triphenylamine is donor and substituted corrole is acceptor by implementing electron donating and withdrawing groups at meso-phenyl rings 5,15-pheny-10-triphenylaminecorrole TPACor 1, 5, 15-di(3,5-ditertbutylphenyl)-10-triphenylaminecorrole TPACor 2, and 5,15-(4-nitrophenyl)-10-triphenylaminecorrole TPACor 3. All three dyads were characterized by various spectroscopic techniques. The absorption spectra of TPACor $\mathbf{3}$ is red shifted due to the presence of electron withdrawing nitro group in its molecular structure. DFT studies indicated that HOMO is on TPA as well as corrole and LUMO is on corrole moiety of these dyad systems. Singlet state properties indicate that when excited at $300 \mathrm{~nm}$, where TPA and Corrole absorb equally, quenched emission spectra were observed in all three dyads, and appearance of corrole emission peak at $680 \mathrm{~nm}$ in all three dyads 
except TPACor 3 in polar solvents. The results showed that there is efficient energy transfer from triphenylamine to corrole in these dyad systems. The quenching efficiency was found to be $>90 \%$ in all three dyads and there is not much substitution effect.

\section{Supplementary Information (SI)}

Figures S1-S17 are available in Supplementary Information at www.ias.ac.in/chemsci.

\section{Acknowledgements}

We are grateful to Department of Science and Technology for financial support for this work (DST SB/S1/IC-14/2014). KS thanks UGC for a research fellowship.

\section{References}

1. El-Khouly M E and Fukuzumi S 2016 Light harvesting a gold porphyrin-zinc phthalocyanine supramolecular donor-acceptor dyad Photochem. Photobiol. Sci. 15 1340

2. Sudhakar K, Gokulnath S, Giribabu L, Lim G N, Tram T and D'Souza F 2015 Ultrafast photoinduced charge separation leading to high-energy radical ion pairs indirectly linked corrole- $\mathrm{C}_{60}$ and triphenylamine-corrole$\mathrm{C}_{60}$ donor-acceptor conjugates Chem. Asian J. 102708

3. Kelber B J, Panjwani N A, Wu D, Gomez-Bombarelli R L, Lovett B W, Morton J J L and Anderson H L 2015 Synthesis and investigation of donor-porphyrinacceptor traids with long-lived photoinduced chargeseparate states Chem. Sci. 66468

4. D'Souza F and Ito O 2009 Supramolecular donoracceptor hybrids of porphyrins/phthalocyanines with fullerenes/carbon nanotubes: Electron transfer, sensing, switching, and catalytic applications Chem. Commun. 4913

5. Sundström V 2008 Dynamics of light harvesting in photosynthesis Annu. Rev. Phys. Chem. 5953

6. Benniston A C and Harriman A 2008 Artificial photosynthesis Materials Today 1126

7. Gust D and Moore T A 2000 In The Porphyrin Handbook K M Kadish, K M Smith and R Guilard R (Eds.) (New York, San Diego: Academic Press) 8153

8. Gust D, Moore T A and Moore A L 2001 Mimicking photosynthetic solar energy transduction Acc. Chem. Res. 3440

9. Moser C C, Keske J M, Warncke K, Farid R S and Dutton P L 1992 Nature of biological electron transfer Nature 355796

10. Duvva N, Sudhakar K, Badgurjar D, Chitta R and Giribabu L 2015 Spacer controlled photoinduced intramolecular electron transfer in a series of phenothiazine-boron dipyrromethane donor-acceptor dyads J. Photochem. Photobiol. A Chem. 3128
11. Gilbert M 2015 Photoinduced charge and energy transfer in molecular wires Chem. Soc. Rev. 44845

12. Giribabu L, Reeta P S, Kanaparthi R K, Srikanth M and Soujanya Y 2013 Bis(porphyrin)-anthraquinone triads: Synthesis, spectroscopy, and photochemistry J. Phys. Chem. A 1172944

13. Marzalek S, Naqane S, Ichake A, Humphry-Baker R, Paul V, Zakeeruddin S M and Gratzel M 2012 Tuning spectral properties of phenothiazine based donor- $\pi$ acceptor dyes for efficiency dye-sensitized solar cells $J$. Mater. Chem. 22889

14. Giribabu L, Kumar Ch V and Reddy P V 2007 Axial bonding heterotrimers based on tetrapyrrolic rings: Synthesis, characterization, and redox and photophysical properties Chem. Asian J. 21574

15. Koszarna B and Gryko D T 2006 Efficient synthesis of meso-substituted corroles in a $\mathrm{H}_{2} \mathrm{O}-\mathrm{MeOH}$ mixture $J$. Org. Chem. $\mathbf{7 1} 3707$

16. Paoless R, Jaquinod L, Nurco D J, Mini S, Sagone F, Boschi T and Smith K M 1999 5,10,15Triphenylcorrole: A product from a modified Rothemund reaction Chem. Commun. 1307

17. Gross Z, Galilina G and Smikhovich L 1999 Epoxidation catalysis by a Manganese corrole and isolation of an oxomanganese(V) corrole Angew Chem. Int. Ed. $\mathbf{3 8}$ 1427

18. Ventura B, DegliEsposti A, Koszarna B, Gryko D T and Flamigni L 2005 Photophysical characterization of freebase corroles, promising chromophores for light energy conversion and singlet oxygen generation New J. Chem. 291559

19. Ding T, Aleman E A, Modarelli D A and Ziegler C J 2005 Photophysical properties of a series of free-base corroles J. Phys. Chem. A 1097411

20. Paolesse R, Marini A, Nardis S, Froiio A, Mandoj F, Nurco D J, Prodi L, Montalti M and Smith K M 2003 Synthetic protocols for the nitration of corroles $J$. Porphyrins Phthalocyanines 725

21. Giribabu L and Sudhakar K 2005 Photoinduced intramolecular reactions in triphenylamine-corrole dyads J. Photochem. Photobiol. A Chemistry 29611

22. Tasior M, Gryko D T, Pielacinska D J, Zanelli A and Flamigni L 2010 Trans A2B corroles bearing a courmarine moiety - from synthesis to photophysics Chem. Asian J. 5130

23. Kandhadi J, Yeduru V, Bangal $P$ R and Giribabu L 2015 Corrole-ferrocene and corrole-anthraquinone dyads: Synthesis, spectroscopy and photochemistry Phys. Chem. Chem. Phys. 1726607

24. Pomarico G, Vecchi A, Mandoj F, Bortolini O, Cicero D O, Galloni P and Paolesse R 2014 The corrole and ferrocene marriage: 5,10,15triferrocenylcorrolato $\mathrm{Cu}$ Chem. Commun. 504076

25. Shi L, Liu H-Y, Peng K-M, Wang X-L, You L-L, Lu J, Zhang L, Ji H W L-N and Jiang H-F 2010 Synthesis of phenothiazine-corrole dyads: The enhanced DNA photocleavage properties Tetrahedron Lett. 513439

26. Balsukuri N, Dasa S and Gupta I 2015 Carbazolecorrole and carbazole-prophyrin dyads: Synthesis, fluorescence and electrochemical studies New J. Chem. 39 482 
27. Giribabu L, Jain K, Sudhakar K, Duvva N and Raghu Ch 2016 Light induced intramolecular electron and energy transfer events in rigidly linked boron dipyrromethene: Corrole Dyad J. Lumin. 177209

28. Giribabu L, Kandhadi J, Kanaparthi R K and Giribabu L 2014 Excitational energy and photoinduced electron transfer reactions in $\mathrm{Ge}(\mathrm{IV})$ corrole-porphyrin hetero dimers J. Lumin. 145357

29. Giribabu L, Kandhadi J and Kanaparthi R K 2014 Phosphorus(V)corrole- porphyrin based hetero trimers: Synthesis, spectroscopy and photochemistry J. Fluoresc. 24569

30. Lewandowska K, Barszcz B, Graja A, Bursa B, Biadasz A, Wrobel D, Bednarski W, Waplak S, Grzybowski M and Gryko D T 2013 Absorption and emission properties of the corrole-fullerene dyad Synth. Met. 166 70

31. Flamigni L, Wyrostek D, Voloshchuk R and Gryko D T 2010 Solvent polarity effect on intramolecular electron transfer in a corrole-naphthalene bisimide dyad Phys. Chem. Chem. Phys. 12474

32. Flamigni L, Ciuciu A I, Langhals H, Bçck B and Gryko D T 2012 Improving photoinduced charge separation parameters in corrole-perylene carboximide dyads by tuning the redox and spectroscopic properties of the components Chem. Asian J. 7582

33. Sudhakar K, Kanaparthi R K, Kumar Ch K and Giribabu L 2014 Synthesis and photophysical properties of a novel corrole-anthraquinone-corrole molecular system J. Lumin. 15334

34. Stefanelli M, Masroianni M, Nardis S, Licoccia S, Fronczek F R, Smith K M, Zhu W H, Ou Z P, Kadish K M and Paolesse P 2007 Functionalization of Corroles: The Nitration Reaction Inorg. Chem. 4610791

35. Stefanelli M, Pomarico G, Tortora L, Nardis S, Fronczek F R, McCandless G T, Smith K M, Manowong M, Fang Y Y, Chen P, Kadish K M, Rosa A, Ricciardi G and Paolesse R $2012 \beta$-Nitro-5,10,15-tritolylcorroles Inorg. Chem. 516928

36. Pomarico G, Fronczek F R, Nardis S, Smith K M and Paolesse R 2011 Synthetic protocols for the nitration of corroles J. Porphyrins Phthalocyanines 151085

37. Singh P, Saltsman I, Mahammed A, Goldberg I, Tumanskii B and Gross Z 2012 Iron complexes of tris(4nitropheny)corroles, with emphasis on the (nitrosyl)iron complex J. Porphyrins Phthalocyanines 16663

38. Geier G R, Chick J F B, Callinan J B, Reid C G and Auguscinski W P 2004 A survey of acid catalysis and oxidation conditions in the two-step, one-flask synthesis of meso-substituted corroles via dipyrromethane dicrbinols and pyrrole J. Org. Chem. 694159

39. Littler B J, Miller M A, Hung C-H, Wagner R W, O'Shea D F, Boyle P D and Lindsey J S 1999 Refined synthesis of 5-substituted dipyrromethanes $J$. Org. Chem. 641391

40. Schuster D I, MacMahon S, Guldi D M, Echegoyen L and Braslavsky S E 2006 Synthesis and photophysics of porphyrin-fullerene donor-acceptor dyads with conformationally flexible linkers Tetrahedron 621928

41. Guifen L, Wensheng L, Yuanyuan F, Weihua Z, Xuelin J and Zhongping O 2011 Synthesis and electrochemical properties of meso-phenyl substituted corroles: Solvent effect on copper oxidation state J. Porphyrins Phthalocyanines $\mathbf{1 5} 1265$

42. Seo K D, Lee M J, Song H M, Kang H S and Kim H K 2012 Novel D- $\pi$-A system based on zinc porphyrin dyes for dye-sensitized solar cells: Synthesis, electrochemical, and photovoltaic properties Dyes Pigm. 94 143

43. Reeta P S, Kanaparthi R K and Giribabu L 2013 $\beta$-pyrrole substituted porphyrin-pyrene dyads using vinylene spacer: Synthesis, characterization and photophysical properties J. Chem. Sci. 125259

44. Frisch M J, Trucks G W, Schlegel H B, Scuseria G E, Robb M A, Cheeseman J R, Scalmani G, Barone V, Mennucci B, Petersson G A, Nakatsuji H, Caricato M, Li X, Hratchian H P, Izmaylov A F, Bloino J, Zheng G, Sonnenberg J L, Hada M, Ehara M, Toyota K, Fukuda R, Hasegawa J, Ishida M, Nakajima T, Honda Y, Kitao O, Nakai H, Vreven T, Montgomery J A, Peralta J E, Ogliaro F, Bearpark M, Heyd J J, Brothers E, Kudin K N, Staroverov V N, Kobayashi R, Normand J, Raghavachari K, Rendell A, Burant J C, Iyengar S S, Tomasi J, Cossi M, Rega N, Millam N J, Klene M, Knox J E, Cross J B, Bakken V, Adamo C, Jaramillo J, Gomperts R, Stratmann R E, Yazyev O, Austin A J, Cammi R, Pomelli C, Ochterski J W, Martin R L, Morokuma K, Zakrzewski V G, Voth G A, Salvador P, Dannenberg J J, Dapprich S, Daniels A D, Farkas O, Foresman J B, Ortiz J V, Cioslowski J and Fox D J, Gaussian 09, Revision B.01, Gaussian, Inc., Wallingford CT (2010)

45. Becke A D 1993 Density functional thermochemistry. III. The role of exact exchange J. Chem. Phys. 985648

46. Petersson G A and Al-Laham M A 1991 A complete basis set model chemistry. II. Open shell systems and the total energies of the first row atoms J. Chem. Phys. 946081

47. Miertus S, Scrocco E and Tomasi J 1981 Electrostatic interaction of a solute with a continuum. A direct utilization of $\mathrm{ab}$ initio molecular potentials for the prevision of solvent effects J. Chem. Phys. 55117

48. Cossi M, Barone V, Cammi R and Tomasi J 1996 Ab initio study of solvated molecules: A new implementation of the polarizable continuum model Chem. Phys. Lett. 255327

49. O'Boyle N M, Tenderholt A L and Langner K M 2008 cclib: A library for package-independent computational chemistry algorithms J. Comput. Chem. 29839

50. Dennington R, Keith $\mathrm{T}$ and Millam J, GaussView, version 5, Semichem Inc, Shawnee Mission KS (2009)

51. Ghosh A and Jynge K 1997 Molecular Structures and Energetics of Corrole Isomers: A Comprehensive Local Density Functional Theoretical Study Chem.-Eur. J. 3823

52. Ding D, Harvey J D and Ziegler C J 2005 Novel routes to substituted 5,10,15-triarylcorroles J. Porphyrins Phthalocyanines 922

53. Stefanelli M, Pomarico G, Tortora L, Nardis S, Fronczek F R, McCandless G T, Smith K M, Manowong M, Fang Y, Chen P, Kadish K M, Rosa A, Ricciardi G 
and Paolesse R $2012 \beta$-Nitro-5,10,15-tritolylcorroles Inorg. Chem. $\mathbf{5 1} 6928$

54. Giribabu L and Maiya B G 1999 Intramolecular energy transfer in a protoporphyrin-(anthracene) $)_{2}$ triad Res. Chem. Intermed. 25769

55. Spieser S 1996 Photophysics and mechanisms of intramolecular electronic energy transfer in bichromophoric molecular systems: Solution and supersonic jet studies Chem. Rev. 941953

56. Forster Th 1959 10th Spiers Memorial Lecture. Transfer mechanisms of electronic excitation Discuss. Faraday Soc. 277
57. Dexter D L 1953 A theory of sensitized luminescence in solids J. Chem. Phys. 21836

58. J R Lakowicz 1999 in Principles of Fluorescence Spectroscopy $2^{\text {nd }}$ Edition (Netherlands: Kluwer Academic Publishers) pp. 368-369

59. Tasior M, Gryko D T, Cembor M, Jaworski J S, Ventura B and Flamigni L 2007 Photoinduced energy and electron transfer in 1,8-naphthalimide-corrole dyads New J. Chem. 31247

60. Lindsey J S, Brown P A and Siesel D A 1989 Visible light-harvesting in covalently-linked porphyrin-cyanine dyes Tetrahedron $\mathbf{4 5} 4845$ 